\title{
Impact of Valuation Ranking Information on Bidding in First-Price Auctions: A Laboratory Study
}

by

\author{
A. Alexander Elbittar
}

\begin{abstract}
Landsberger et al. (2001) identified optimal bidder behavior in first-price private-value auctions when the ranking of valuations is common knowledge, and derived comparative-statics predictions regarding the auctioneer's expected revenue and the efficiency of the allocation. The experiment reported here tests the behavioral components of these comparative-statics predictions. The results support the prediction that buyers are inclined to bid more aggressively when they learn they have the low value. Contrary to the theory, buyers are inclined to bid less when they learn they have the high value. Once information is revealed, bidders tend to move toward better responses, exploiting new economic opportunities. Consistent with theory, the overall proportion of efficient allocations is lower than in the first-price auction before information is revealed. But as a result of high-value bidders decreasing their bids, the expected revenue does not increase on a regular basis, contrary to the theory's predictions.
\end{abstract}

Keywords: Asymmetric auctions, laboratory experiments, bounded rationality, affiliation and economics of information.

Journal of Economic Literature Classification Numbers: C92, D44, D82.

\footnotetext{
${ }^{*}$ I would like to express my thanks to Masaki Aoyagi, Vincent Crawford, David Kaplan, Vijay Krishna, Todd Kaplan, John Miller, Stephen Morris, Charlie Plott, Philip Reny, Jean-François Richard, Tridib Sharma, Matthew Shum, Utku Ünver, Elmer Wolfstetter, Shmuel Zamir and two anonymous referees, as well as seminar participants at CIDE, Hewlett-Packard, ITAM, ESA Summer Meeting 2000, and Econometric Society Winter Meeting 2001 for their comments. I am especially grateful to John Kagel for his support and many helpful discussions and suggestions. All errors are mine. Partial support from Asociación Mexicana de Cultura is also acknowledged.

Address: Instituto Tecnológico Autónomo de México, Centro de Investigación Económica, Camino a Santa Teresa 930, México, D.F., México, 10700. E-mail: elbittar@itam.mx.
} 


\section{Introduction}

Traditional auction models assume that agents do not know how their valuations stand relative to those of their rivals, with knowledge limited to the underlying distribution from which values are drawn. In real-life situations, this is often an unrealistic assumption since agents know more than this. Such would be the case in procurement auctions, where due to accumulated experience, bidders might learn who the strongest bidder is. There is also a general perception that, in privatizations, firms already in the market or, in takeovers, firms with related activities have a greater valuation than potential entrants or competing firms. For instance, in the recent privatization of airwaves in the US, there was a general perception that the Pacific Telephone Company had a greater valuation for the Los Angeles area than did the other similar potential bidders. Another example would be the auctioning of the third generation mobile phone licenses in the UK, where firms already in the market were believed to have greater valuations for the new licenses being sold than similar potential entrants. ${ }^{1}$ The relevance of information revelation on bidding behavior is a common factor to all of these examples, some of them using different auction formats. Thus, there is currently a need to determine the impact of information revelation on bidding behavior in auction markets, on seller's revenue, and on the efficiency of the auction outcome. ${ }^{2}$

Early theoretical contributions in auction theory considered the symmetric and independent private-values model: a single unit auction under the assumptions of

\footnotetext{
${ }^{1}$ Further examples include art auctions, where bidders might revise their bidding strategies based on the participation of a wealthy art collector who is known to have a high valuation. In the selling process of Wellcome, a drug company, it was commonly known that Wellcome and Glaxo had particular synergies that made Wellcome worth more to Glaxo than to any other competing firms (Klemperer, 2003). Fang and Morris (2003) quote situations where bidders can obtain some information about similar opponents' estimates via insider rumors and industrial espionage. Looking form the seller's perspective, Kaplan and Zamir (2002) cite situation in which a seller knows the object's worth to each buyer, which provides him valuable information to obtain additional rents.

${ }^{2}$ For a description of the importance of information revelation in auction markets, see Krishna (2002), Klemperer $(2003)$ and Wolfstetter $(1996,1999)$ for recent surveys in the theoretical research, and Kagel (1995) for a survey in the experimental research.
} 
bidders' risk neutrality, independence of bidders' reservation values and symmetry of bidders' beliefs (Vickrey, 1961; Myerson, 1982; Riley and Samuelson, 1981). Milgrom and Weber (1982) provided comparative-statics predictions regarding the impact of public information on the revenue ranking among different auctions institutions with affiliated private-values. ${ }^{3}$ In that case, bidders' private values are no longer independent, but are still symmetric. Introducing asymmetry in the distributions while preserving independence, Maskin and Riley (2000) and Plum (1992) provided some revenue ranking propositions between the second-price and first-price auctions, based on stochastic dominance across distributions. Relaxing simultaneously the assumptions of independence and symmetry, Landsberger, Rubinstein, Wolfstetter and Zamir (2001) - hereafter referred to as LRWZ - developed a theoretical model in which two bidders draw their values from the same distribution, but the ranking of these valuations is common knowledge. The auction is ex-ante symmetric since bidders' valuations are drawn independently from a single density distribution. However, the revelation of the rankings makes it affiliated and asymmetric since the subsequent conditional distributions differ. ${ }^{4}$

In this paper, I concentrate on evaluating experimentally the comparative-statics predictions derived by LRWZ (2001). In particular, I report the results of an auction experiment in which two bidders are required to bid for a single item following a firstprice sealed-bid allocation rule and under two different information conditions. While each bidder knows the value of the item to herself, the revelation of the valuation

\footnotetext{
${ }^{3}$ In auctions with affiliated private-values, values might remain private for bidders, but the higher (lower) the value is for one bidder, the more likely the value will be higher (lower) for other bidders as well (Milgrom and Weber, 1982).

${ }^{4}$ Fang and Morris (2003) have followed a similar approach to LRWZ in the context of multidimensional private value auctions. In particular, they consider parametric examples of two bidder private value auctions in which valuations are drawn from the same distribution and each bidder observe a noisy signal about her opponent's private valuation. Among other results, they show that for the first price auction inefficiency increase as the signal becomes more informative. Kaplan and Zamir (2000) also study theoretically the strategic use of seller information using LRWZ as a baseline. In their work, the seller can increase his expected revenue by committing to a signaling strategy to both bidders. For more on information in asymmetric auctions see Kim and Che (2004) and McAdams (2004).
} 
ranking induces a particular asymmetric affiliation between bidders' valuations. ${ }^{5}$

The experiment reported here evaluates the key predictions of LRWZ's model regarding the auctioneer's expected revenue and the efficiency of the first-price auction in cases when the ranking of valuations is common knowledge to two bidders: (i) The bidder with the lower reservation value will bid more aggressively than the high-value bidder. Thus, the proportion of efficient allocations should be lower than when the bidders lack information about the ranking of valuations. (ii) Bidders are expected to bid more aggressively than in the standard first-price auction model, in which information regarding the ranking of valuations is not available. (iii) For a number of distributions, including the uniform distribution studied here, the seller's expected revenue should be higher when rankings are known than when they are unknown.

These comparative-statics predictions are founded on two behavioral components: For the low-value bidder, the more aggressive bidding behavior is an immediate consequence of knowing her position. Meanwhile, for the high-value bidder, the more aggressive bidding behavior is a consequence of incorporating her expectations about the low-value bidder response to her strategy. Note that this behavior presumes a higher level of strategic thinking for the high-value bidder. If the high-value bidder does not take the low-value bidder's more aggressive bidding into consideration, she might be tempted to bid less in an attempt to take advantage of her higher valuation.

The current paper is closely related to previous auction experiments where individuals can use information strategically. In the context of affiliated private-values, Kagel, Harstad and Levin (1987) tested the effects of public information about rivals' valuations on the seller's expected revenue (Milgrom and Weber, 1982). In that paper, bidders are required to bid for a single item following a first-price sealed-bid allocation rule and under two different information conditions. ${ }^{6}$ While each bidder knows the value of the item to herself, the revelation of a public signal induces a

\footnotetext{
${ }^{5}$ While for Milgrom and Weber (1982) the affiliation is among symmetric distributions of signals, LRWZ (2001) consider a model in which the affiliation is among asymmetric distribution of signals.

${ }^{6}$ Kagel et al. (1987) also tested similar predictions for the second-price sealed bid and english auctions.
} 
particular symmetric affiliation between bidders' valuations. As a consequence, the low-value bidder should raise her bid in an effort to win the item once she has realized she has a lower valuation than she had assumed prior to the announcement of the public signal. In turn, this should put pressure on the high-value bidder to raise her bid, resulting in more expected revenue for the seller. In the context of independent private-values, but with values drawn from different distributions, Pezanis-Christou (2000) and Güth, Ivanova-Stenzel and Wolfstetter (2004) concentrated on testing predictions derived respectively by Maskin and Riley (2000) and Plum (1992). In those papers, one strong-bidder and one weak-bidder are required to bid for a single item following a first-price sealed-bid allocation rule, where the weak-bidder is more likely to draw values lower than the strong-bidder. ${ }^{7}$ While in Pezanis-Christou (2000) the weak-bidder has a positive probability of not bidding at all, in Güth et al. (2004) the upper bound of the distribution for the weak-bidder is smaller than for the strongbidder. In both cases, the strong bidder has an incentive to low-ball; that is, to submit low bids for a range of low values. ${ }^{8}$

As mentioned earlier, the main goal of these experimental papers is to evaluate qualitative predictions when individuals can use information strategically. Kagel et al. (1987) showed that the revelation of information about others' valuations increases average bidding and market prices. However, the increase in prices is closer to the predictions of the risk-averse Nash equilibrium (RANE) model, which permits some increase in revenue lower than the predicted by the risk-neutral Nash equilibrium (RNNE) model. Meanwhile, Pezanis-Christou (2000) and Güth et al. (2004) showed that although the strong-bidder is willing to low-ball, the reduction in the average bidding and market prices is not as significant as expected when compared to the second-price auction.

The experimental results of this paper support the prediction that low-value bid-

\footnotetext{
${ }^{7}$ These papers also compared bidding behavior and seller's expected revenue between second-price and first-price sealed bid allocation rules.

${ }^{8}$ In a follow up paper, Pezanis-Christou and Sadrieh (2003) explore a similar issue eliciting bidders' bid functions.
} 
ders are inclined to bid more aggressively once information about the ranking of valuations has been revealed. Contrary to the predictions of the theory, high-value bidders are inclined to bid less aggressively. Thus, consistent with the theory, the overall proportion of efficient allocations is lower than in the first-price auction before information is revealed. But as a result of high-value bidders decreasing their bids, the expected revenue does not increase consistently. Although both kinds of bidders improve their average payoff per auction by moving toward the asymmetric RNNE after information is revealed, high-value bidders continue to bid above it. The RANE model seems an alternative way to explain why high-value bidders may bid above the RNNE (Cox, Smith and Walker, 1988). However, risk aversion should induce the same changes in behavior as predicted by the risk-neutral model. In order to reconcile these experimental results, a high-value bidders' best response is derived assuming that they are risk-averse and that they do maximize with respect to the empirical low-value bidders' bid function. The resulting high-value bidders' bid function reflects their incentives to reduce their bids after information is revealed and the tendency to bid above the RNNE.

The experimental results of this paper are also related to the research on beliefs that people have about others' beliefs and their behavior in response to those beliefs. This line of research has focused on testing the degree of subjects' strategic sophistication (Camerer, 2003). For the LRWZ's model, the main theoretical predictions are based on the fact that the low-value bidder should not violate dominance by bidding the same or lower after knowing her position. It is also expected that the high-value bidder's response should incorporate her expectations about the low-value bidder response into her strategy and should not violate dominance by bidding lower after knowing her position. Previous experimental studies have evaluated simple games where iteration of dominance eliminate one, two or three strategies (see, for example, Beard and Beil, 1994 and Schotter, Weigelt and Wilson, 1994). These studies have found little support for more than one step of deletion of dominant strategies. Although few subjects violate dominance, most of them seem unwilling to bet heavily 
that others will obey dominance. Trying to measure the number of steps of iterated elimination of weakly dominated strategies, Nagel (1999) studied strategic reasoning in the beauty contest game. She found that a typical participant uses one or two steps of reasoning. One feature of the way this game is played is that subjects who think just one step ahead of the median population should do better than those who iterate further. Other studies have looked at games in which iterated reasoning decreases payoffs (see, for example, McKelvey and Palfrey, 1992), and games in which iterated reasoning increases payoffs (see, for example, Capra, Goeree, Gomez and Holt, 2002). The results of this experimental study indicate that low-value bidders seem to obey dominance in general by bidding higher, though a large proportion of the deviations from this prediction involve no change in bids. Meanwhile, high-value bidders increase their average payoff conditional on winning by becoming less aggressive. This can still be explained either as a failure to take into account low-value bidders' response to the revelation of the ranking and/or as a consequence of increasing her eagerness to take advantage of her comfortable position to increase her monetary profits.

This paper is organized as follows. Section 2 describes the experimental design. Section 3 specifies the RNNE bidding strategies for the auction models and states the comparative-statics predictions for the first-price auction when the information about the ranking of valuations is revealed. Section 4 evaluates the experimental results regarding these auctions settings. Section 5 summarizes the research results.

\section{Experimental Design}

The experimental design used directly measures the information impact of the ranking of valuations on bidding behavior in first-price private-values auctions. The particulars of the experimental design follow. 


\subsection{Structure of the Auction}

Subjects in this experiment are required to bid for a single item following a firstprice sealed-bid allocation rule under two different information conditions. In the first-price sealed-bid auction, the high bidder earns a payoff equal to her value of the item less the high bid, while the other subject earns nothing. In one information condition (hereafter referred to as symmetric condition), two private values, one for each bidder, are independently drawn from a commonly known uniform distribution. In the symmetric condition bidders have no information about the rank order of valuations. In the second information condition (hereafter referred to as asymmetric condition), both bidders are informed about the rank order of their valuations before bidding, whether they have the highest or lowest valuation (but not informed about the size of the differences in valuations.)

\subsection{Dual-Market Bidding Procedure}

A dual-market bidding was employed. In the dual-market, bidders just submit a bid under the symmetric condition. Then, once these bids are collected, but before they are posted, information about the ranking of valuations is released and subjects are asked to then submit a second bid. The winner in each market is determined after the second bid is submitted. Payoffs are determined based on just one of the two markets (chosen with equal probability). Participants' positions as high-value or low-value bidder are determined randomly in each period.

The dual-market bidding procedure, involving the same two bidders bidding for the same item under two different information conditions, has the advantage of directly controlling for between-subject variability in bidding. ${ }^{9}$ The rule of flipping a fair coin to determine which market to pay in ensures that, under the expected utility hypothesis, the optimal strategy in the private information market should be unaffected by bids made after the ranking is revealed, and vice-versa.

\footnotetext{
${ }^{9} \mathrm{~A}$ similar procedure has been used in previous auction experiments by Kagel and Levin (1986) and Kagel, Harstad and Levin (1987).
} 
Table 1: Experimental Design

\begin{tabular}{|c|c|c|c|c|}
\hline $\begin{array}{c}\text { Experimental } \\
\text { Treatment }\end{array}$ & Sessions & $\begin{array}{l}\text { Auction } \\
\text { Periods }\end{array}$ & Markets & $\begin{array}{l}\text { Information } \\
\text { Condition }\end{array}$ \\
\hline \multirow{2}{*}{$\begin{array}{l}\text { Asym. Condition and } \\
\text { Dual-Market Bidding }\end{array}$} & \multirow[t]{2}{*}{$1 \& 2$} & 1 to 10 & Single-Auction & Asymmetric \\
\hline & & 11 to 30 & Dual-Auction & Sym./Asym. \\
\hline \multirow{2}{*}{$\begin{array}{l}\text { Sym. Condition and } \\
\text { Dual-Market Bidding }\end{array}$} & \multirow[t]{2}{*}{$3 \& 4$} & 1 to 10 & Single-Auction & Symmetric \\
\hline & & 11 to 30 & Dual-Auction & Sym./Asym. \\
\hline
\end{tabular}

Note: In session 1, during the dual-auction markets, only 18 trading periods (out of 20) were actually run since the network system broke down at that stage.

In order to determine whether the dual-market bidding procedure actually affects the way bidders bid, and to familiarize subjects with the auction conditions so as to make it easier for them to bid in dual-auction markets, each session began with bidding in single-auction markets. For the single-auction markets, each bidder submitted one bid in each period. Table 1 briefly summarizes the experimental treatments. Sessions 1 and 2 began with ten periods of single-auction markets with the asymmetric condition followed by twenty periods of dual-auction markets. During these ten initial periods, each bidder maintained her role as a high-value or low-value bidder. ${ }^{10}$ Sessions 3 and 4 began with ten periods of single-auction markets with the symmetric condition followed by twenty periods of dual-auction markets.

\subsection{Design Parameters}

This section characterizes the basic parameters and the general procedure of the experiment.

Valuation Distribution. All bidders were informed that their valuations were drawn randomly from the interval $\$ 0.00$ to $\$ 6.00$ and that any value in this interval has an equally likely chance of being draw. Valuations were any penny amount

\footnotetext{
${ }^{10}$ There is certainly the possibility of randomizing the roles of being low-value and high-value bidders in the asymmetric auctions, favoring learning in the bidding procedure once roles change. However, we keep subjects in fixed positions in order to maximize the prospect that rivalrous elements will come into play, allowing us to make a stronger comparison against the situation when players did not know the ranking.
} 
from 0.01 up to $6.00 .^{11}$

Payoff Mechanism and Participation Fee. Each group of players received an initial cash balance of zero. Players were paid in cash the total earnings obtained from each auction period, plus a participation fee, at the end of the experiment. Since bidders' roles were not changed during the initial ten auction periods of sessions 1 and 2, the low-value bidders received an additional $\$ 5$ at the end of each session. Players were informed at the beginning about this additional payment. This was a fixed amount that was not expected to impact behavior.

Matching Procedure. Bidders were informed that participants would be randomly matched in every period, but that no pair of bidders would be matched twice in two consecutive periods. Bidders were also informed that, in the dual-auction markets section, each of them would face the same opponent (with the same valuation) in both markets.

Information Feedback. At the end of every period each player got the following information. For the single-auction markets with the asymmetric condition, each subject received feedback about her earnings and the competing bidder's valuation and bid. For the single-auction markets with the symmetric condition, additional information about the ex-post ranking of valuations was posted on the computer screens. For the dual-auction markets, each subject received complete feedback about who the high bidder was in each market, as well as her earnings in each market, what the other bidder's value and bids were in each market, and which market was randomly selected to pay off in. Subjects' identifications were not revealed.

Dry Runs. In order to familiarize subjects with the auction procedures, two practice periods occurred at the beginning of the single-auction markets, and one practice period occurred just before the dual-auction markets began.

Subjects. For each session, subjects were drawn from a wide cross-section of students (mostly undergrads) at the University of Pittsburgh and Carnegie Mellon Uni-

\footnotetext{
${ }^{11}$ Actually, the valuations mean for low-value and high-value bidders were 2.00 and 4.00 , respectively, while the standard error was 0.05 for both cases.
} 
versity. There were 18 subjects for session 1 and 20 subjects for sessions 2,3 and 4 . Subjects participated in only one session. The experiment was run in the economics lab at the University of Pittsburgh using computers. ${ }^{12}$

\section{Theoretical Predictions}

LRWZ consider the specific situation where a single object is auctioned between two bidders. Both bidders have risk-neutral utility functions and independently drawn private valuations. These valuations are ex-ante identically distributed according to a differentiable cumulative distribution function, which is common knowledge to bidders. Each bidder knows whether she has the higher or the lower valuation but does not know her opponent's exact valuation.

LRWZ proved that there exists a unique equilibrium in pure strategies that is strictly increasing with regard to the valuation. It should be noted that LRWZ's analysis is not trivial and works with a non-standard ordinary differential equation system, which lacks an analytical solution. Under the assumption that the underlying distribution of valuations is uniform with the support $[0,6]$, both agents maximization problems can be reduced to the following differential equation system by the first order necessary conditions:

$$
\begin{gathered}
l^{\prime}(b)(h(b)-b)=l(b) \\
h^{\prime}(b)(l(b)-b)=h(b)-l(b) \\
h(0)=l(0)=0 \\
\exists b^{*} \in[0,6] \text { such that } h\left(b^{*}\right)=l\left(b^{*}\right)=6
\end{gathered}
$$

where $l(\cdot)$ and $h(\cdot)$ are the inverse bid functions of $b_{L}$ and $b_{H}$, respectively. By l'Hôpital's Rule, $h^{\prime}(0)=2$ and $l^{\prime}(0)=\frac{4}{3}$. Notice that in equilibrium, $v_{L}=l(b)$ when

\footnotetext{
${ }^{12}$ The site http://ciep.itam.mx/ elbittar/instructions/lrwz.pdf contains the set of instructions given to subjects.
} 
$L$ bids $b$, and $v_{H}=h(b)$ when $H$ bids $b$. For a numerical approximation of the above system of equations, I follow a general method implemented by Elbittar and Ünver (2001).

The bidding response for the symmetric and independent private-values first-price auction model, $b_{S}$, can be derived analytically. For the case of $n$ risk neutral bidders with a uniform distribution, the unique symmetric Nash Equilibrium bid function is $b_{S}(v)=\frac{(n-1)}{n} v$ (Vickrey, 1961).

The equilibrium bidding response for the low-value bidder and for the high-value bidder are represented in Figure 1 by $b_{L}$ and $b_{H}$, respectively. In the same graphic, the equilibrium bidding response for the symmetric and independent private-values model when $n=2$ is represented by $b_{S} \cdot{ }^{13}$

\subsection{Comparative-Statics Predictions}

The comparative-statics predictions of these two auction models define the theoretical benchmark for measuring the possible impact of valuation ranking revelation on bidding behavior. These predictions also provide us with precise statements about the changes in the seller's revenue and the proportion of optimal allocations. First, the high-value bidder should bid less aggressively than the low-value bidder for any given value $\left(b_{L}(v)>b_{H}(v), \forall v \in(0,6)\right)$. Since the low-value bidder can obtain the item with positive probability, the proportion of efficient allocations should decrease. Second, for a number of different distributions, including the case of uniform distribution studied here, revealing the ranking should induce the low-value bidder to bid

\footnotetext{
${ }^{13}$ The discreteness of the strategy space introduced in the experimental design does not have an effect on the equilibrium bid functions and the resulting predictions. Athey (2001) has proved that pure strategy Nash equilibria (PSNE) exists in every finite-action game under single crossing condition. That is, "whenever each opponent uses a nondecreasing strategy, a player's best response strategy is also nondecreasing." Furthermore, there exists a sequence of PSNE to finite-action games that converges to a PSNE of the continuum-action game for games with continuous payoffs and a continuum of actions. These conditions are satisfied in first-price auctions with general affiliated private values with two bidders, as it is in our case. For this experiment, the average difference between the Nash bid and the Nash bid truncated using the last two decimals is of $\$ 0.0025$ with an standard error of $0.6406 \times 10^{-3}$, which is not significantly different from zero.
} 


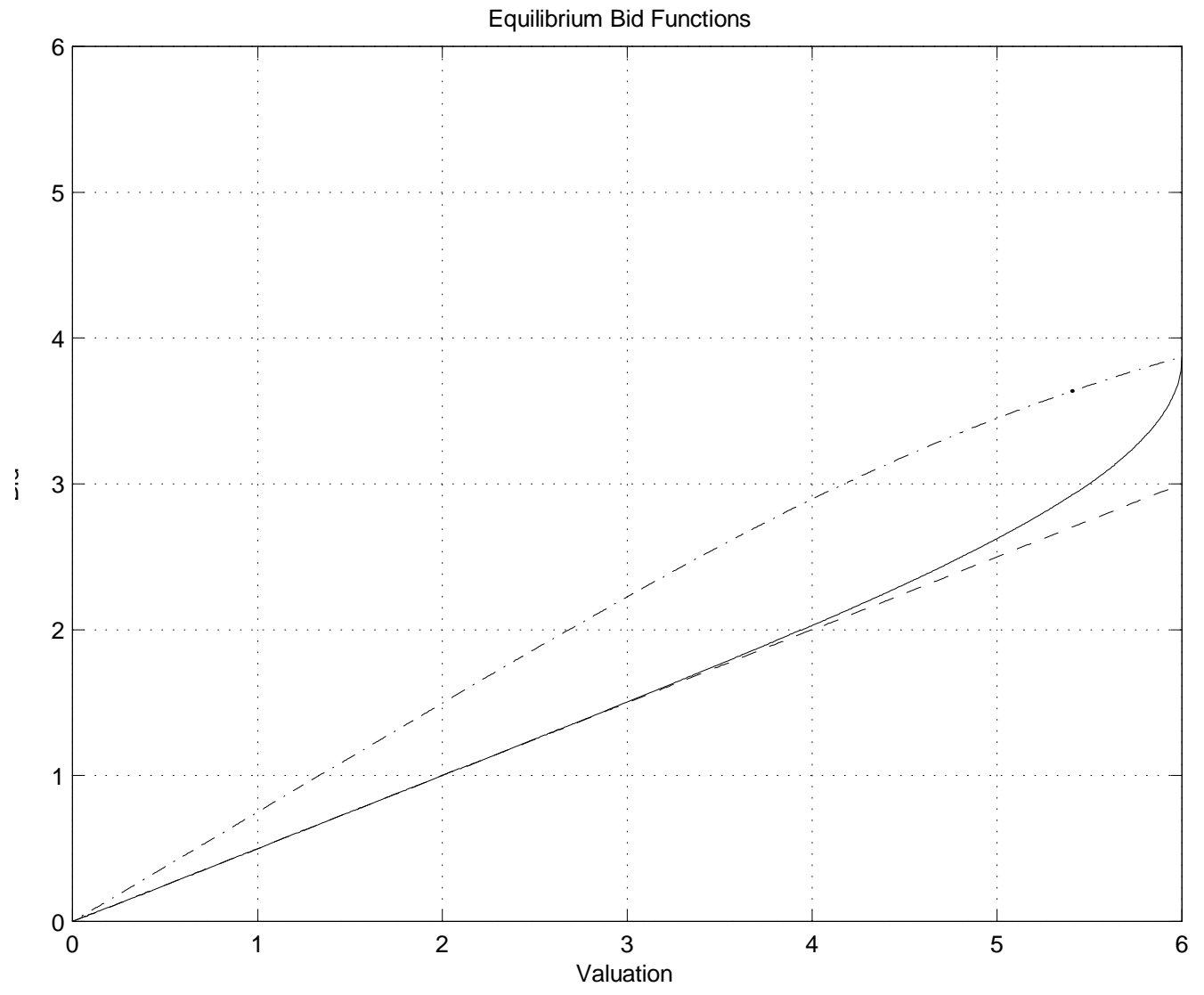

Figure 1: Equilibrium Bid Functions: $b_{L}(v)[-\cdot], b_{H}(v)[-]$ and $b_{S}(v)[--]$ 
strictly higher than when this information is not known $\left(b_{L}(v)>b_{S}(v), \forall v \in(0,6]\right)$. It should also induce the high-value bidder to bid the same for valuations below or equal to 4 and the strictly higher for valuations above $4\left(b_{H}(v)=b_{S}(v)\right.$, whenever $v \in(0,4]$ and $b_{H}(v)>b_{S}(v)$, whenever $\left.v \in(4,6]\right)$. Therefore, the seller's expected revenue should increase. ${ }^{14}$

These changes are associated with two behavioral components, both producing positive effects on the seller's expected revenue (Maskin and Riley, 2000). One component is the "sure thing effect": The high-value bidder must take into consideration that the low-value bidder is willing to increase her bid in order to increase her probability of winning the object. Note that the high-value bidder must think more deeply to formulate the right response compared to the low-value bidder. However, if the high-value bidder does not take the low-value bidder's more aggressive bidding into consideration, she could be tempted to bid less in a misguided attempt to take advantage of her higher valuation. The second behavioral component would be the "weight effect": The low-value bidder must bid more aggressively once she is informed about her position. Therefore, since the low-value bidder is expected to bid more aggressively than the high-value bidder, the higher bid is weighted more in the expected revenue due to the higher probability of winning.

Table 2 summarizes some important theoretical predictions for both auction models using the equilibrium bid functions. The seller's expected revenue, the proportion of Pareto-Optimal Allocations (POA), the proportion of the maximal payoff - or Mean Efficiency (ME) -, and each type of bidder's conditional expected payoff and probability of winning the item are numerically estimated, drawing valuations from the uniform distribution in the interval $[0,6]$. The values used in these results indicate that the theoretical impact of the valuation ranking revelation would increase the seller's expected revenue from $\$ 2.00$ to around $\$ 2.22$, with the percentages of POA and of ME decreasing from $100.0 \%$ to $71.0 \%$ and $95.7 \%$, respectively.

\footnotetext{
${ }^{14}$ This will always be true for the low-value bidder. However, for the high-value bidder, LRWZ showed that there exist probability distributions for which $b_{S}(v)>b_{H}(v)$ for some values of $v$.
} 
Table 2: Numerical Results from the Equilibrium Bid Functions

\begin{tabular}{|c|c|c|c|c|c|c|c|c|c|}
\hline \multirow{2}{*}{$\begin{array}{c}\text { Auction } \\
\text { Model }\end{array}$} & \multirow{2}{*}{$\begin{array}{c}\text { Sellers } \\
\text { Revenue }\end{array}$} & \multicolumn{2}{|c|}{ Regular Buyer } & \multicolumn{2}{|c|}{ High-Value } & \multicolumn{2}{|c|}{ Low-Value } & \multirow{2}{*}{$\begin{array}{c}\text { Proportion } \\
\text { of } \mathrm{POA}^{a}\end{array}$} & \multirow[b]{2}{*}{$\mathrm{ME}^{b}$} \\
\hline & & Payoff & $\operatorname{Pr}[$ Win] & Payoff & $\operatorname{Pr}[$ Win] & Payoff & $\operatorname{Pr}[$ Win] & & \\
\hline Symmetric* & 2.000 & 1.000 & 0.500 & $(-)$ & $(-)$ & $(-)$ & $(-)$ & 1.000 & 1.000 \\
\hline Asymmetric & 2.219 & $(-)$ & $(-)$ & 1.361 & 0.710 & 0.263 & 0.290 & 0.710 & 0.957 \\
\hline
\end{tabular}

Note: Valuations are drawn from the uniform interval $[0,6]$. Mean is computed by Monte Carlo using 10,000 samples of 1,000 drawings.

*: Calculations are made analytically.

${ }^{a}$ : Pareto-Optimal Allocations: POA

${ }^{b}$ : Mean Efficiency: $M E=\frac{v_{w i n}}{v_{h}}$

Table 3: Observed Bid Factors

\begin{tabular}{|c|c|c|c|c|c|}
\hline & \multicolumn{3}{|c|}{$\begin{array}{c}\text { Bid Factor* } \\
\text { Symmetric }\end{array}$} & \multicolumn{2}{c|}{$\begin{array}{c}\text { Bid Factor } \\
\text { Asymmetric } \\
\text { Condition }\end{array}$} \\
\cline { 2 - 6 } Statistics & $\delta_{L}^{S}(v)$ & $\delta_{H}^{S}(v)$ & $\delta^{S}(v)$ & $\delta_{L}^{A}(v)$ & $\delta_{H}^{A}(v)$ \\
\hline \hline Median & 0.303 & 0.342 & 0.326 & 0.180 & 0.393 \\
Mean & {$[0.333]$} & {$[0.356]$} & {$[0.344]$} & {$[0.243]$} & {$[0.400]$} \\
s.e. & $(0.007)$ & $(0.006)$ & $(0.005)$ & $(0.008)$ & $(0.006)$ \\
\hline
\end{tabular}

Note 1: $\delta^{S}$ is the aggregation of $\delta_{L}^{S}$ and $\delta_{H}^{S}$.

*: Bid Factor: $\delta_{i}^{j}=\frac{v-b(v)}{v}, i=\mathrm{L}, \mathrm{H}$ and $j=\mathrm{S}, \mathrm{A}$. 


\section{Experimental Results}

This section compares the experimental results for the dual-auction markets in order to directly measure how revealing the ranking of valuations affects bidding behavior. ${ }^{15,16}$

\subsection{Bidding Behavior}

Table 3 reports the observed bid factor, $\delta_{i}^{j}(v)$, for each type of bidder, and each information condition. The bid factor, or relative difference between subjects' valuations and bids, tells us how much a bidder shaves off her own reserve value when bidding for an item.

LRWZ predict that both types of bidders bid more aggressively under the asymmetric condition than under the symmetric condition $\left(\delta_{i}^{S}(v)>\delta_{i}^{A}(v), i=\mathrm{L}, \mathrm{H}\right)$.

Analysis of the actual bid factors in Table 3 indicates that, contrary to expectations, $\delta_{H}^{S}(v)<\delta_{H}^{A}(v)$. For the pooled data, the high-value bidders shave off in average 4.4 percentage points more after information is released, which is about 15 cents per auction. Although bids according to Figure 1 do not begin to increase measurably until valuations exceed 4 , bidding reduction happen in the whole range of valuations. Bidders with valuations less than 4 shave off in average 6.4 percentage points in average more after information is released, which is about 16 cents per auction. Meanwhile, bidders with valuations greater than 4 shave off 2.9 percentage points in average, which is about 15 cents per auction. Thus, high-value bidders tend to bid lower under the asymmetric condition. By contrast, low-value bidders tend to discount less after information about the ranking of valuations is released. For the

\footnotetext{
${ }^{15}$ As we will see in each of the following sections, the results of single-auction markets are consistent with the results for the dual-auction markets and indicate that the dual-market bidding procedure does not to affect the bidding behavior.

${ }^{16}$ The total number of bids from both market is 1524 . However, some observations were excluded from the statistical analysis: Either because the subject's bidding was above her own valuation (18 observations), or the subject's valuation was less than two cents, so the corresponding symmetric RNNE was less than a cent (10 observations). The final number of observations over which I concentrate the analysis is 1496 .
} 
Table 4: Matched Pairs Wilcoxon Test Statistic for Comparison of Bid Factors

\begin{tabular}{|c|l|c|c|c|c|}
\hline $\begin{array}{c}\text { Auction } \\
\text { Period }\end{array}$ & ${ }^{a} W_{L}$ & $W_{H}$ & $\begin{array}{c}\text { Auction } \\
\text { Period }\end{array}$ & $W_{L}$ & $W_{H}$ \\
\hline \hline 11 & $2.724^{* *}$ & -0.560 & 21 & $3.907^{* * *}$ & -1.988 \\
\hline 12 & $1.666^{*}$ & -2.183 & 22 & $3.256^{* * *}$ & -1.154 \\
\hline 13 & $2.607^{* *}$ & -1.609 & 23 & $4.411^{* * *}$ & -2.886 \\
\hline 14 & $3.391^{* * *}$ & -2.198 & 24 & $3.743^{* * *}$ & -2.986 \\
\hline 15 & $2.621^{* *}$ & -2.812 & 25 & $3.021^{* *}$ & -1.512 \\
\hline 16 & $4.223^{* * *}$ & -1.406 & 26 & $4.413^{* * *}$ & -3.464 \\
\hline 17 & $2.326^{* *}$ & -3.151 & 27 & $3.406^{* * *}$ & -1.669 \\
\hline 18 & $3.067^{* *}$ & -3.431 & 28 & $4.460^{* * *}$ & -2.707 \\
\hline 19 & $1.972^{*}$ & -1.476 & 29 & $2.977^{* *}$ & -0.446 \\
\hline 20 & $3.464^{* * *}$ & -2.707 & 30 & $3.275^{* * *}$ & -3.036 \\
\hline
\end{tabular}

pooled data, the same bidders shave off 9.0 percentage points less after information is released, which is about 23 cents per auction. As expected, low-value bidders tend to bid higher under the asymmetric condition. ${ }^{17}$

Table 4 displays, for every auction period, a one-tailed Matched Pairs Wilcoxon $\left(W_{i}\right)$ test statistic for each group of players type $i$. The null hypothesis that the bid factor for low-value bidders under the symmetric condition is lower than or equal to that under the asymmetric condition is rejected in all auction periods. For high-value bidders, however, the same null hypothesis holds for all auction periods.

Based on the second of the comparative-statics predictions, it is expected that high-value bidders bid less aggressively than low-value bidders for any given value

\footnotetext{
${ }^{17}$ For the single-auction markets, the results are similar to those for the dual-auction markets i.e., low (high) value bidders under the asymmetric condition tend to bid more (less) aggressively than bidders under the symmetric condition. For the pooled data, the low-value bidders shave off 11.1 percentage points less in the asymmetric auctions than in the symmetric auctions. The highvalue bidders shave off 4.0 percentage points more in the asymmetric auctions than in the symmetric auctions. Using a one-tailed Rank-Order test statistic, the null hypothesis that the bid factor for the low-value bidders under the symmetric condition is lower than or equal to this factor under the asymmetric condition is rejected for every period. However, for the high-value bidders, the same null hypothesis is not rejected for every period.
} 
Table 5: Estimated Parameters of Bid Functions

\begin{tabular}{|c|c|c|l|c|c|}
\hline \multirow{2}{*}{ Bid Function } & \multicolumn{5}{|c|}{ Estimates } \\
\cline { 2 - 6 } & $\widehat{\alpha}$ & $\widehat{s}(\widehat{\alpha})$ & \multicolumn{1}{|c|}{$\widehat{\beta}$} & $\widehat{s}(\widehat{\beta})$ & $\widehat{R}^{2}$ \\
\hline \hline$\widehat{b}_{S}$ & $0.651^{*}$ & 0.023 & $1.024^{*}$ & 0.015 & 0.840 \\
$\widehat{b}_{L}$ & $0.680^{*}$ & 0.046 & $1.073^{*+}$ & 0.018 & 0.758 \\
$\widehat{b}_{H}$ & $0.548^{*}$ & 0.037 & $1.026^{*}$ & 0.022 & 0.699 \\
\hline
\end{tabular}

*: Reject $H_{0}: \beta=0.0$ or $H_{0}: \alpha=0.0$ for $p<0.001$

${ }^{+}$: Reject $H_{0}: \beta=1.0$ for $p<0.001$

Table 6: Difference of Estimated Bid Factors

\begin{tabular}{|c|c|c|c|}
\hline \multicolumn{4}{|c|}{ Difference } \\
\hline Statistics & $\widehat{\delta}_{H}^{A}(v)-\widehat{\delta}_{L}^{A}(v)$ & $\widehat{\delta}^{S}(v)-\widehat{\delta}_{L}^{A}(v)$ & $\widehat{\delta}^{S}(v)-\widehat{\delta}_{H}^{A}(v)$ \\
\hline Mean & 0.163 & 0.104 & -0.059 \\
\hline s.e. & $\left(1.12 \times 10^{-5}\right)$ & $\left(1.11 \times 10^{-5}\right)$ & $\left(1.36 \times 10^{-5}\right)$ \\
\hline
\end{tabular}

under the asymmetric condition $\left(b_{L}(v)>b_{H}(v)\right)$. In order to better assess this prediction, it is necessary to estimate and compare subjects' actual bid functions for the same valuation. In order to estimate the actual bid functions, I consider the following non-linear specification: $b_{i t}=\alpha v_{i t}^{\beta}$, where $b_{i t}$ is the player $i$ 's bid sent in period $t$ and $v_{i t}$ is the player $i$ 's valuation in period $t$. Notice, first, that this specification encompasses both a lineal and a non-linear model, where $\beta$ and $\alpha$ characterize the curvature degree of the actual bid function. Second, that an increment (a reduction) in $\beta$ would represent a more (less) responsive behavior for the same group of bidders. Third, that $\alpha$ would represent the shaving proportion out of the reservation value when $\beta$ is equal to one.

Table 5 reports the estimated parameters of each regression, $\widehat{\alpha}$ and $\widehat{\beta}$, using the pooled data. ${ }^{18}$ This table also reports the standard deviation of the estimates, $\widehat{s}(\cdot)$, as well as the $R$-squared, $\widehat{R}^{2}$, for the each of the bid functions. $\widehat{b}_{L}$ and $\widehat{b}_{H}$ correspond to

\footnotetext{
${ }^{18}$ To account for individual agent variability, I used a random effect model. For these estimations, the fixed effect estimates do not differ significantly from the random effect estimates.
} 


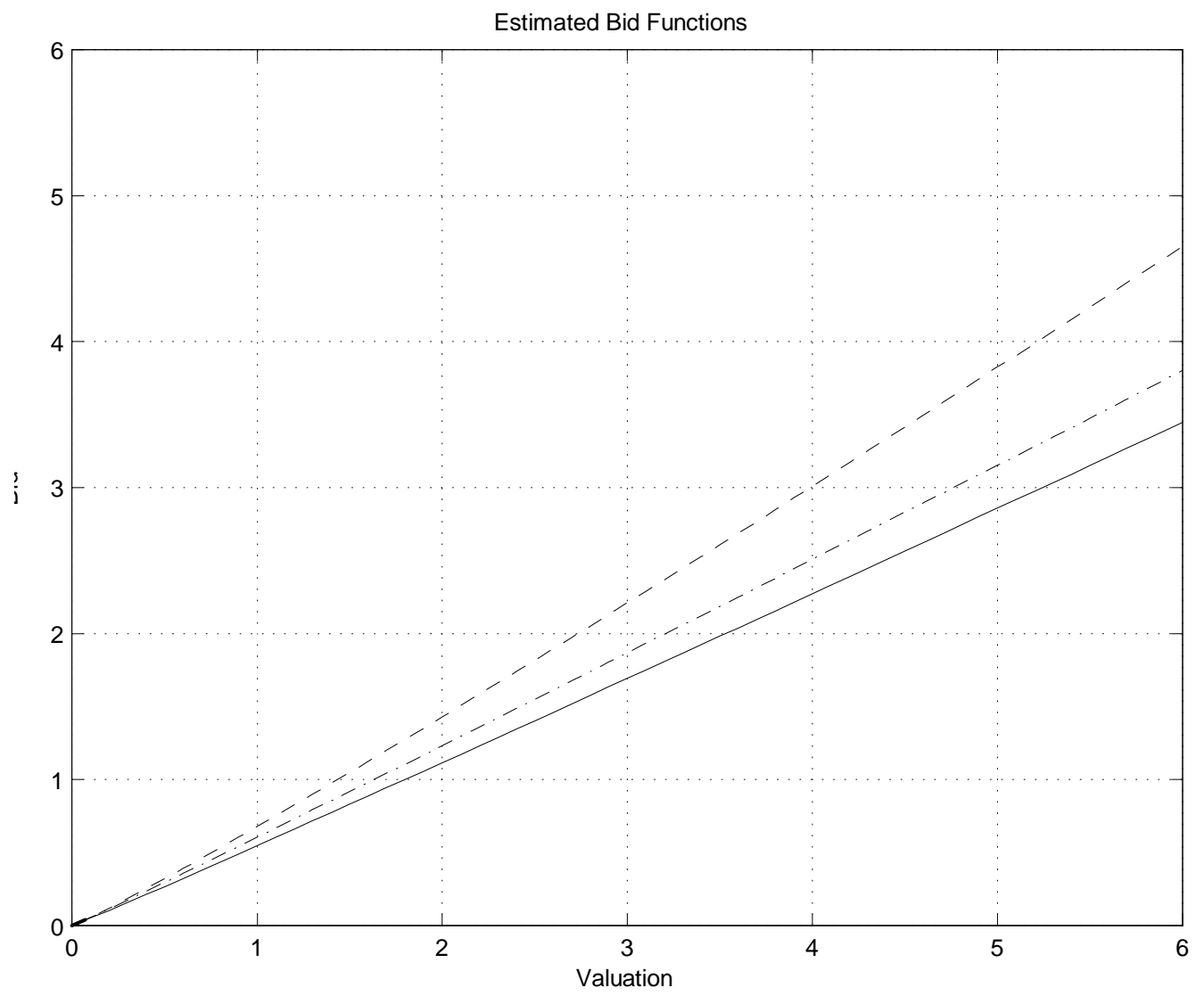

Figure 2: Estimated Bid Functions: $\widehat{b}_{S}(v)[-\cdot], \widehat{b}_{H}(v)[-]$ and $\widehat{b}_{L}(v)[--]$

the estimated bid functions under the asymmetric condition for low-value and highvalue bidders, respectively. Meanwhile, $\widehat{b}_{S}$ corresponds to the estimated bid function under the symmetric condition. All coefficients are significantly different from zero for a $p<0.001$. Since the $\widehat{\beta}$ coefficients for $\widehat{b}_{S}$ and $\widehat{b}_{H}$ are not significantly different from one, these two bid functions seem highly linear. Figure 2 graphs each of the estimated bid functions. From these estimations, it is not perceived the existence of a common ceiling in bids.

Table 6 reports the mean of the difference in bid factors evaluated for the same set of random draws. ${ }^{19}$ The mean of the difference in bid factors between low and

\footnotetext{
${ }^{19}$ Valuations were drawn from the common support of the bid functions. Mean and standard error
} 
high-value bidders, $\widehat{\delta}_{H}^{A}(v)-\widehat{\delta}_{L}^{A}(v)$, represents a significant difference in bidding behavior. ${ }^{20}$ Specifically, high-value bidders shave off their reserve value approximately 16.3 percentage points higher than low-value bidders. Thus, for the same set of random draws, low-value bidders, on average, bid 55 cents more than high-value bidders. This difference can be broken down into two components. The first component is the mean of the difference in bid factors between low-value bidders under both conditions, $\widehat{\delta}^{S}(v)-\widehat{\delta}_{L}^{A}(v)$. In particular, low-value bidders shave off their reserve value around 10.4 percentage points less under the asymmetric condition than under the symmetric one, thus representing an additional bidding of approximately 37 cents. The second component is the mean of the difference between the bid factors of high-value bidders in both conditions, $\widehat{\delta}^{S}(v)-\widehat{\delta}_{H}^{A}(v)$. High-value bidders shave off their reserve value around 5.9 percentage points more under the asymmetric condition than under the symmetric one, resulting in a lower bidding of approximately 18 cents.

In conclusion, bid functions estimates based on the experimental data indicate that revealing the ranking of valuations induces low-value bidders to bid more than highvalue bidders with the same valuation. This result is consistent with the comparativestatic prediction of LRWZ. It also supports our previous finding that low-value bidders tend to bid more aggressively under the asymmetric condition and high-value bidders are inclined to bid less aggressively.

Using the pooled data, Tables 7 reports how individual subjects alter their bids following the announcement of the valuation ranking. For the upper part of this table, each entry is the percentage of values drawn in a particular range, as in the row heading, for which high-value bidders respond as in the column heading. The same information is shown for low-value bidders. As said, LRWZ predict that high-value were computed by Monte Carlo using 10,000 samples of 1,000 drawings.

${ }^{20}$ In order to assess the accuracy of the estimated bid functions, we compare the estimated bid factors using the same set of valuations drawn in the experiment and the direct estimated bid factors available from the experiment (See Table 3). The null hypothesis that the estimated bid factors for high-value and low-value bidders in the asymmetric environment are each equal to those estimated in the experiment cannot be rejected for $p<0.05$. 
Table 7: Effects of Valuation Ranking Information on Bidders' Bids

\begin{tabular}{|c|c|c|c|}
\hline \multirow{2}{*}{ Valuation Range } & \multicolumn{3}{|c|}{ Bids } \\
\cline { 2 - 4 } & $b_{H}(v)<b_{S}(v)$ & $b_{H}(v)=b_{S}(v)$ & $b_{H}(v)>b_{S}(v)$ \\
\hline \hline $6 \geq v>4$ & $52.5 \%$ & $19.9 \%$ & $27.6 \%$ \\
\hline $4 \geq v>0$ & $57.9 \%$ & $21.2 \%$ & $20.9 \%$ \\
\hline $6 \geq v>0$ & $54.9 \%$ & $20.5 \%$ & $24.6 \%$ \\
\hline \hline Valuation Range & $b_{L}(v)<b_{S}(v)$ & $b_{L}(v)=b_{S}(v)$ & $b_{L}(v)>b_{S}(v)$ \\
\hline $6 \geq v>0$ & $13.7 \%$ & $22.2 \%$ & $64.1 \%$ \\
\hline
\end{tabular}

bidders will raise their bids for valuations above 4 and keep them the same for valuations below or equal to 4 . As shown in Table 7, a sizable proportion of high-value bidders decrease their bids over the whole support (54.9\%), which can be counted as violations of the comparative-statics predictions. For valuations above 4 , the proportion of violations is even larger: $52.5 \%$ decreasing their bids and $19.2 \%$ bidding the same. For valuations below 4, the proportion of violations is also larger: $57 \%$ decreasing their bids and $20.9 \%$ increasing their bids. The same model predicts that low-value bidders will raise their bids. As shown in the same table, low-value bidders increase their bid in $64.1 \%$ of the observations, with large majority of deviations from this prediction $(22.2 \%)$ involving no change in bids. ${ }^{21}$

In conclusion, low-value bidders seem in general to obey dominance by bidding higher. Meanwhile, there is an indication of a larger variation in the response of highvalue bidders than in that of low-value bidders. This result could be attributed to the greater complexity of bidding strategies for high-value bidders once information is released. For low-value bidders, the obvious response to such information is to increase their bids in order to increase the probability of obtaining the object. For high-value bidders, the response is less obvious: Once high-value bidders are aware of their strong position, they might either be reluctant to take on the risk of submitting

\footnotetext{
${ }^{21}$ Kagel et al. (1987) found that a large percentage of bidders increase their bids after a public signal was revealed $(67 \%)$, while a large majority of deviations from this prediction involved no change in bids (between $17 \%$ and $27 \%$ ).
} 
Table 8: Probability of Modifying Bidding Behavior

\begin{tabular}{|c|c|c|c|c|c|c|}
\hline \multirow[b]{2}{*}{ Probability } & \multicolumn{6}{|c|}{ Estimates } \\
\hline & $\widehat{\alpha}$ & $\widehat{s}(\widehat{\alpha})$ & $\widehat{\beta}_{1}$ & $\widehat{s}\left(\widehat{\beta}_{1}\right)$ & $\widehat{\beta}_{2}$ & $\widehat{s}\left(\widehat{\beta}_{2}\right)$ \\
\hline$\overline{P P\left(b_{S}>b_{H}\right)}$ & $1.834^{* * *}$ & 0.422 & $-0.198^{*}$ & 0.079 & "0.610* & 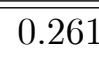 \\
\hline$P\left(b_{L}>b_{S}\right)$ & $-0.903^{* *}$ & 0.285 & $0.695^{* * *}$ & 0.087 & $0.633^{* *}$ & 0.244 \\
\hline
\end{tabular}

lower bids because of low-value bidders' more aggressive bidding behavior or be willing to take such a risk in hopes of increasing their average payoff. ${ }^{22,23}$ This behavior do not change over time. However, the probability of a high-value bidder decreasing her bids is positively correlated and significant with respect to a similar action in a previous period. Table 8 reports the estimates of the probability that a high-value bidder decreases her bid after information is released: $P\left(y_{i t}=1\right)=F\left(\alpha+\beta_{1} v_{i t}+\beta_{2} y_{i t-1}\right)$, where $F\left(z_{i}\right)=\frac{1}{1+e^{-z_{i}}}$ is the cumulative logistic distribution function; $y_{i t}=1$ means that a bid was reduced, $b_{i t}^{S}>b_{i t}^{H}, v_{i t}$ is the player $i$ 's valuation in period $t$; and $y_{i t-1}$ is a dummy equal to one when bidder $i$ decided to reduce or keep the same bid in the previous period she was a high-value bidder. Similar results are found for low-value bidders, when the dependent variable is equal to one if the bid has been increased, $b_{i t}^{L}>b_{i t}^{S}$. The positive sign of $\widehat{\beta}_{2}$ indicates that a high-value (low-value) bidder tend to decrease (increase) her bid more frequently when she had taken the same choice in a previous period acting in the same role. As it is shown below, high-value (low-value) bidders' behavior seemed to be reinforced by the fact that by decreasing (increasing) their bids, they could improve their average payoff conditional on winning.

\footnotetext{
${ }^{22}$ This kind of mixed response for high-value bidders is observed at individual level too. The frequency mode for high-value bidders decreasing their bids is 0.50. For low-value bidders, the frequency mode of increasing their bid is 1 .

${ }^{23}$ At the end of the sessions, subjects were asked to write down what their bidding strategies were once they learned their positions as either high-value bidder or low-value bidder. Most of answers were as follow: "If I was a low I raised my bid. While, if I was a high I lowered my bid." Just a few participants indicated an apparently more sophisticated reasoning: "Once I knew I was a high bidder, I usually lowered my bid. Sometimes I highered (sic) it because I knew the other person knew they were a low bidder, so they might also increase their bid."
} 
Table 9: Overbidding Factor

\begin{tabular}{|c|c|c|c|c|c|c|}
\hline \multirow{2}{*}{$\begin{array}{c}\text { Overbidding } \\
\text { Factor } \\
\end{array}$} & \multicolumn{6}{|c|}{ Estimates } \\
\hline & $\widehat{\alpha}$ & $\widehat{s}(\widehat{\alpha})$ & $\widehat{\beta}_{1}$ & $\widehat{s}\left(\widehat{\beta}_{1}\right)$ & $\widehat{\beta}_{2}$ & $\widehat{s}\left(\widehat{\beta}_{2}\right)$ \\
\hline$\widehat{\lambda}_{S}$ & $0.187^{* * *}$ & 0.013 & $-0.015^{* * *}$ & 0.003 & $0.063^{* * *}$ & 0.019 \\
\hline$\widehat{\lambda}_{L}$ & -0.026 & 0.021 & $0.026^{* * *}$ & 0.005 & -0.004 & 0.030 \\
\hline$\widehat{\lambda}_{H}$ & $0.362^{*}$ & 0.081 & $-0.043^{* *}$ & 0.015 & $0.322^{*}$ & 0.096 \\
\hline
\end{tabular}

\subsection{Do bidders bid at equilibrium?}

The baseline of the comparative-static predictions in LRWZ is what risk-neutral, fully rational bidders bid under the symmetric condition. Well known pattern of bidding above RNNE in first-price independent private value auctions is replicated here, as well as for the high-value bidders in the asymmetric condition. The overbidding factor, $\lambda_{i}=\frac{b_{i}(v)-b_{i}^{*}(v)}{v_{i}}, i=\mathrm{L}, \mathrm{H}, \mathrm{S}$, is the relative deviation of the actual bid with respect to the RNNE bid. The mean of the overbidding factor under the symmetric condition is 15.6 percentage points more than the RNNE response, which represents 44 cents. Under the asymmetric condition, the mean of the overbidding factor for high-value bidders is around 8.0 percentage points more than the RNNE response, which represents 27 cents. The proportions of bids above the RNNE are 82.6 and 68.9 percent, respectively. ${ }^{24}$ Although a significant proportion of low-value bidders bid above the RNNE (67.8 percent), the overbidding factor is 1.6 percentage points, which is not significantly different from zero. ${ }^{25}$ This percentage difference represents 9 cents. $^{26}$

\footnotetext{
${ }^{24}$ Using a one-tailed binomial test statistic on the observed bids compared with the theoretical bids, the null hypothesis that the proportion of actual bids above the RNNE is lower than or equal to 50 percent is rejected for all auction markets within each information condition for $p<0.01$.

${ }^{25}$ This is confirmed by a one-tailed Kolmogorov-Smirnov test on observed bids against theoretical bids at every period.

${ }^{26}$ For the single-auction markets, a pattern of overbidding behavior is found under the symmetric condition. Under the asymmetric condition, a similar pattern is found for high-value bidders, while not for low-value bidders.
} 
The comparative-statics predictions have been derived in a static framework focusing on equilibrium behavior. However, often it takes quite some time for an equilibrium to emerge and repeated interaction gives subjects a change to experiment in order to make better choices. Experimental results indicate that bidding behavior for the symmetric bidders and for the high-value bidders move respectively toward each of the RNNE over time. In contrasts, low-value bidders' bidding behavior do not change over time. Using the pooled data, Table 9 reports the estimates of the following specification: $\lambda_{i t}=\alpha+\beta_{1} v_{i t}+\beta_{2}$ per $_{t}$, where $\lambda_{i t}$ is the player $i$ 's overbidding factor at period $t, v_{i t}$ is the player $i$ 's valuation in period $t$, and per is the inverse of the time period, per $=\frac{1}{t} \cdot{ }^{27,28}$ The time trend coefficient, $\widehat{\beta}_{2}$, is significant for both symmetric bidders and high-value bidders with a positive coefficient value indicating lower bidding over time. However, they seem to converge at lower rates, keeping bidders bounded away from the RNNE. By the last period, the mean of the overbidding factor under the symmetric condition is 16.7 percentage points more than the RNNE response, which represents 40 cents. Under the asymmetric condition, the mean of the overbidding factor for high-value bidders is around 5.4 percentage points more than the RNNE response, which represents 17 cents by the same period. Finally, the time trend coefficient is not significant for low-value bidders.

The risk-averse Nash equilibrium (RANE) model has been considered as alternative way to accommodate the experimental data because there is a significant number of subjects bidding above the RNNE response (See, for example, Cox,.Smith and Walker, 1988. ${ }^{29}$ The intuition behind this consideration is that aversion toward risky

\footnotetext{
${ }^{27}$ Compared to a linear adjustment, this non-linear specification is superior since it allows a more rapid adjustment and convergence to a stady state behavior. Actually, I could not reject the null hypothesis that the convergence in time is non-linear for the symmetric bidders and for the high-value bidders.

${ }^{28}$ To account for individual agent variability, I used a random effect model. For these estimations, the fixed effect estimates do not differ significantly from the random effect estimates.

${ }^{29}$ There has been a long discussion about the relevance of risk attitude in the context of the firstprice auction to explain deviations from the RNNE. Readers interested should look at Kagel (1995) extensive review of the different positions on this particular issue and the interchange on Harrinson (1989) that took place in the December 82 issue of the American Economic Review.
} 
situations (the risk of not getting the object) would induce a more aggressive behavior. Following the same intuition for our benchmark model, the introduction of a risky parameter (assuming that the individual parameters are stable across different informational environments) would induce an even more aggressive bidding behavior than the one predicted from the risk-neutral model since now high-value bidders would like to reduce more the risk of losing the object knowing that low-value bidders would like to win the object more eagerly. ${ }^{30}$ Therefore, the aversion toward risk should induce the same changes in behavior as predicted by the risk-neutral model. Thus, given the observed changes in behavior, the consistent pattern of overbidding behavior would not be fully consistent in our case with the idea of risk averse bidders since risk aversion would induce a more aggressive bidding behavior of both bidders after information revelation for a given parameter of risk aversion. ${ }^{31}$

\footnotetext{
${ }^{30}$ This can be checked introducing a coefficient of relative risk aversion into the system of differential equations presented by LRWS and working out the numerical solution for a given set of parameter. Under the assumptions that the underlying distribution of valuations is uniform and that both agents are risk averse, both agents maximization problems can be reduced to the following differential equation system by the first order necessary conditions:
}

$$
\begin{gathered}
l^{\prime}(b)(h(b)-b)=r l(b) \\
h^{\prime}(b)(l(b)-b)=r(h(b)-l(b)) \\
h(0)=l(0)=0 \\
\exists b^{*} \in[0,6] \text { such that } h\left(b^{*}\right)=l\left(b^{*}\right)=6
\end{gathered}
$$

where $r(<1)$ is the risk aversion coefficient, being the same for every bidder, and $l(\cdot)$ and $h(\cdot)$ are the inverse bid functions of $b_{L}$ and $b_{H}$, respectively. By l'Hôpital's Rule, $h^{\prime}(0)=1+r$ and $l^{\prime}(0)=\frac{(1+r)^{2}}{(1+2 r)}$. Notice that if $r$ decreases, the slopes of the bid functions close to zero would increase, implying a more aggressive behavior.

${ }^{31}$ Actually, a risk-loving behavior (i.e., a risk parameter greater than one, $r>1$ ) would induce changes in behavior in the opposite direction since now $h^{\prime}(0)>2$. Thus, a high-value bidder would be willing to reduce her bid.

Another relevant question is whether the revelation of information about the ranking might affect subjects' attitudes toward risky situations. The answer to this question goes beyond the original goal of this research paper. There are other papers where a similar question has been addressed using different institutions (Isaac and James, 2000.) 
Table 10: Estimated Bid Functions Comparison: Numerical Results

\begin{tabular}{|c|c|c|c|c|c|c|}
\hline \multirow{2}{*}{$\begin{array}{c}\text { Bid Functions } \\
\text { Comparison }\end{array}$} & Stat. & Seller & \multicolumn{2}{|c|}{ High-Value } & \multicolumn{2}{|c|}{ Low-Value } \\
\cline { 4 - 7 } & Revenue & Payoff & $\operatorname{Pr}[$ Win] & Payoff & $\operatorname{Pr}[\mathrm{Win}]$ \\
\hline \hline$\widehat{b}_{H}(v)$ vs $\widehat{b}_{L}(v)$ & Mean & 2.366 & 1.322 & 0.773 & 0.205 & 0.227 \\
& s.e. & $\left(2.78 \times 10^{-4}\right)$ & $\left(2.82 \times 10^{-4}\right)$ & & $\left(1.26 \times 10^{-4}\right)$ & \\
\hline$\widehat{b}_{S}(v)$ vs $\widehat{b}_{L}(v)$ & Mean & 2.556 & 1.251 & 0.848 & 0.1439 & 0.152 \\
& s.e. & $\left(2.93 \times 10^{-4}\right)$ & $\left(2.25 \times 10^{-4}\right)$ & & $\left(1.12 \times 10^{-4}\right)$ & \\
\hline$\widehat{b}_{H}(v)$ vs $\widehat{b}_{S}(v)$ & Mean & 2.290 & 1.564 & 0.908 & 0.130 & 0.092 \\
& s.e. & $\left(2.60 \times 10^{-4}\right)$ & $\left(2.37 \times 10^{-4}\right)$ & & $\left(1.38 \times 10^{-4}\right)$ & \\
\hline
\end{tabular}

Note: Valuations were drawn from the common support of the bid functions. Mean and standard error were computed by Monte Carlo using 10,000 samples of 1,000 drawings.

\subsection{Do bidders profitably deviate?}

The question to be addressed next is whether there exist monetary incentives for high-value bidders to decrease their bids rather than increase them (or at least keep them approximately the same). In order to check whether such incentives exist, I check whether high-value bidders increase their average payoff by bidding based on the estimated bid function, $\widehat{b}_{H}(v)$, rather than continuing to use the estimated bid function previous to the revelation of the ranking, $\widehat{b}_{S}(v)$.

In Table 10, the first row displays the results of a Monte Carlo experiment in which high-value bidders bid against low-value bidders, with both groups bidding based on the estimated response functions $\widehat{b}_{H}(v)$ and $\widehat{b}_{L}(v)$, respectively. The second row indicates results of a similar numerical experiment in which high-value bidders based their bids on the estimated response before the ranking was revealed, $\widehat{b}_{S}(v)$. Table 10 displays, for each comparison, the seller's expected revenue, the bidder's expected monetary payoff conditional on winning and the probability of winning the item.

The numerical results of Table 10 indicate that, if high-value bidders were using the bid function previous to the revelation of the ranking, $\widehat{b}_{S}(v)$, the unconditional average payoff would drop from $\$ 1.70$ to $\$ 1.48$ per auction (by around 23 cents per auction); meanwhile, the probability of winning the item would increase from 0.77 to 
0.85. As result, their average payoff, conditional on winning, would fall by around 7 cents per auction. Therefore, it is better for high-value bidders to reduce their bids, which in fact is what they do.

For low-value bidders, the question is whether it is better to increase their bids based on the estimated bid function, $\widehat{b}_{L}(v)$, rather than continuing to use the estimated bid function prior the revelation of the ranking, $\widehat{b}_{S}(v)$. The third row of Table 10 reports results of a numerical experiment in which low-value bidders bid based on the estimated response before the revelation of the ranking, $\widehat{b}_{S}(v)$, but high-value bidders based their bids on the estimated bid function after information is revealed, $\widehat{b}_{H}(v)$. Comparing the numerical results of the first and the third rows in Table 10, it is clear that, if low-value bidders were bidding using the bid function previous to the

revelation of the ranking, $\widehat{b}_{S}(v)$, they would suffer a reduction in their average payoff conditional on winning (of around 7 cents per auction).

As general conclusion, it can be claimed that each group of bidders improves the average monetary payoff per auction by properly deviating after information is released. In particular, the revelation of the ranking provides incentives for highvalue bidders to decrease their bids and to obtain additional benefits. However, this behavior can be explained either as a failure to take into account low-value bidders' response to the revelation of the ranking and/or as a consequence of increasing her eagerness to take advantage of her comfortable position to increase her profits.

\subsection{High-Value Bidders' Behavior: An Ex-Post Analyses}

In the previous sections, we have observed that high-value bidders tend to reduce their bids after information is released. Although high-value bidders tend to properly deviate improving the average monetary payoff per auction, they keep bidding above the RNNE. The goal of this section is to try to reconcile these experimental results. With this in mind, I have defined a bidding strategy which might involve less rationality than what theory claims. A plausible strategy should reflect high-value buyers incentives to reduce their bids after information is being revealed and still tend to bid 
above the RNNE.

Let's consider a risk averse bidder that maximize with respect to the other bidder empirical bid function: $b_{j}=\alpha v^{\beta}$. This yields the following bidding response: ${ }^{32}$

$$
b_{i_{r}}\left(v ; r, \beta_{j}\right)=\frac{v}{1+\beta_{j} r}
$$

where $r$ is the coefficient of risk aversion for player $i$ and $\beta_{j}$ is the coefficient of responsiveness for the competing bidder $j$. Notice also that $b_{i_{r}}$ is a decreasing function with respect to $\beta_{j}$. So bidder $i$ becomes less aggressive if the competing bidder $j$ becomes more responsive. The specification of $b_{i_{r}}$ is consistent with the fact that the estimations of $b_{S}$ and $b_{H}$ are highly linear with respect to valuations. Assuming that $r$ does not change across informational environments, I check whether the beta estimate for the low-value bidders, $\widehat{\beta}_{L}$, is greater than the same estimate for the symmetric bidders, $\widehat{\beta}_{S}$, $\left(\widehat{\beta}_{L}>\widehat{\beta}_{S}\right)$ when $b_{S}>b_{H}$. Using a test for the difference between two means of independent samples, we can reject the null that $\beta_{L} \leq \beta_{S}$ for $p<0.0132$. Therefore, if we consider the increment of the beta coefficient as an expression of the bidder $j$ increasing eagerness to get the object, bidder $i$ should be decreasing her bid and still bidding above the RNNE conditional on having the higher valuation than bidder $j$.

\footnotetext{
${ }^{32}$ Under the assumptions that the underlying distribution of valuations is uniform, that agents are risk averse, and that agents perceive the empirical bid function from a competing bidder $j$, a bidder $i$ maximization problem (for the symmetric case and for high-value bidders) can be reduced to the following differential equation by the first order necessary condition:

$$
\begin{gathered}
l^{\prime}(b)(h(b)-b)=r l(b) \\
h(0)=l(0)=0
\end{gathered}
$$

where $r(<1)$ is the risk aversion coefficient, being the same for every bidder, and $l(\cdot)$ and $h(\cdot)$ are the inverse bid functions for bidder $j, b_{j}=\alpha v^{\beta}$, and for bidder $i, b_{i}$, respectively. Since it was not perceived a ceiling in bidding, I do not impose any restriction in the upper bound of the distribution.
} 
Table 11: Effect of Ranking Information on Revenue

\begin{tabular}{|c|c|c|}
\hline \multirow{2}{*}{ Statistics } & $\begin{array}{c}\text { Symmetric } \\
\text { Condition }\end{array}$ & $\begin{array}{c}\text { Asymmetric } \\
\text { Condition }\end{array}$ \\
\cline { 2 - 3 } & $p_{S}$ & $p_{A}$ \\
\hline \hline Mean & 2.610 & 2.572 \\
s.e. & $(0.037)$ & $(0.038)$ \\
Median & {$[2.655]$} & {$[2.620]$} \\
\hline \hline${ }^{a} t$ & \multicolumn{2}{|c|}{-2.049} \\
\hline${ }^{b} W$ & \multicolumn{2}{|c|}{-2.378} \\
\hline
\end{tabular}

${ }^{a}$ : Matched Pairs t-test. $H_{0}: p_{A}(b) \leq p_{S}(b)$

against $H_{1}: p_{A}(b)>p_{S}(b)$.

${ }^{b}$ : Matched Pairs Wilcoxon test. $H_{0}: p_{A}(b)$

$\leq p_{S}(b)$ against $H_{1}: p_{A}(b)>p_{S}(b)$.

*: Reject $H_{0}$ against $H_{1}$ at $p<0.05$.

\subsection{Expected Revenue and Efficiency}

With the high-value bidders decreasing their bids, the enhanced revenue possibilities of the FPA with the ranking of valuations revealed no longer necessarily holds; rather it becomes an empirical question of whether high-value bidders' decreasing bids dominate low-value bidders' increasing bids after information is released.

Table 11 reports the mean, standard error and median of the observed price realization for each information condition. Each average price realization represents the observed seller's expected revenue for a particular information condition $j: p_{j}$, $j=\mathrm{S}, \mathrm{A}$. According to LRWZ, seller's revenue expected to be higher under the asymmetric condition than under the symmetric condition $\left(p_{A}>p_{S}\right)$.

As noted in the statistics in Table 11, however, the mean of the selling prices under the symmetric condition $(\$ 2.61)$ is slightly higher than under the asymmetric condition (\$2.57). This observation is confirmed by a one-tailed Matched Pairs t-test statistic $(t)$, the result of which is displayed at the bottom of the same table. The null hypothesis that the price realization under the symmetric condition is larger than or equal to the price realization under the asymmetric condition could not be rejected, 
Table 12: Effect of Ranking Information on Efficiency

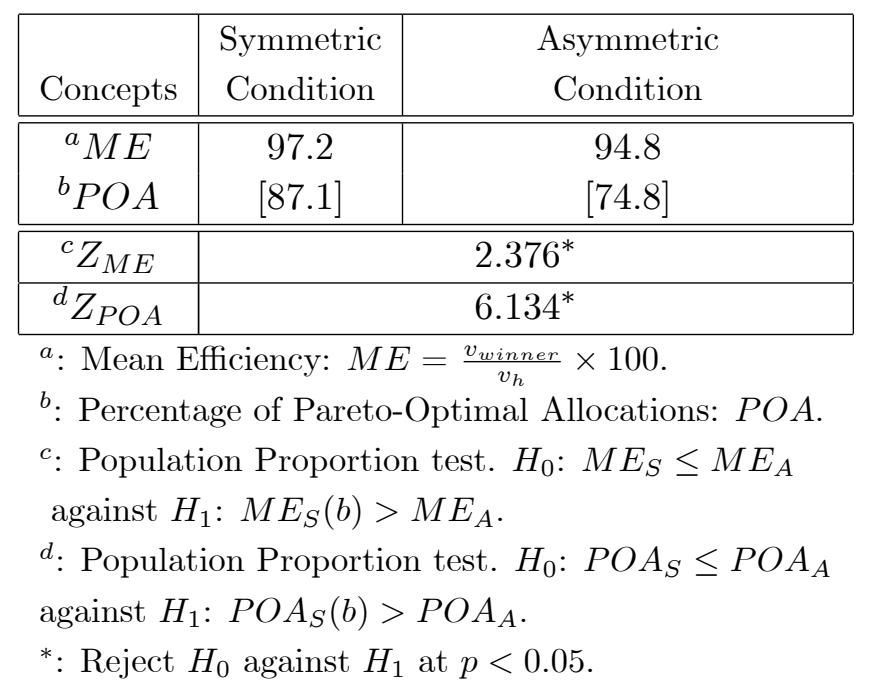

showing that the seller's expected revenue does not always increases after information is released. ${ }^{33}$

In conclusion, the experimental data do not support the prediction that the seller's revenue increases after information about the ranking is released. ${ }^{34}$ As discussed, this is due to a significant reduction of the high-value bidders' response under the asymmetric condition. ${ }^{35}$

Table 12 reports the following two measures of optimal allocation and economic efficiency: i) Pareto-Optimal Allocations (POA), reported as the percentage of ob-

\footnotetext{
${ }^{33}$ Testing for every auction period, the null hypothesis that the price realization under the symmetric condition is larger than or equal to the price realization under the asymmetric condition could not be rejected in nineteen out of the twenty auction periods at $p<0.05$.

${ }^{34}$ For the single-auction markets, the average price realization under the asymmetric condition is not higher than under the symmetric condition. This observation is confirmed by a one-tailed t-test. The null hypothesis that the price realization under the symmetric condition is larger than or equal to the price realization under the asymmetric condition could not be rejected for every auction period for $p<0.05$.

${ }^{35}$ Notice that due to the significant pattern of overbidding behavior, the average revenue for each information condition was significantly higher than the expected revenue at the risk-neutral equilibrium. For the dual-auction markets, the average price realization for the asymmetric (symmetric) condition was $\$ 2.57(\$ 2.61)$. Meanwhile, the expected revenue at equilibrium for the asymmetric (symmetric) condition was $\$ 2.22(\$ 2.00)$.
} 
jects given to the high-value bidder; and ii) Mean Efficiency (ME), reported as the percentage of the maximal payoff that was generated as a result of the auction. ${ }^{36}$ Since low-value bidders generally have a positive probability of obtaining the item, the percentage of efficient allocations was expected to be lower under the asymmetric condition than under the symmetric condition.

As seen in the calculations displayed in Table 12, the percentage of POA and ME are consistently higher under the symmetric condition than under the asymmetric condition. This result is due to the more aggressive bidding of the low-value bidders and to the less aggressive bidding of the high-value bidders under the asymmetric condition. In the same table, a one-tailed Population Proportion $(Z)$ test statistic for each measure of optimal allocation is reported. The null hypothesis is rejected in favor of the alternative hypothesis that the efficiency under the symmetric condition is higher than under the asymmetric condition. ${ }^{37}$

In conclusion, the first-price auction is, in the aggregate, more efficient in the absence of information. ${ }^{38}$ This result confirms the prediction about the reduction of the proportion of optimal allocations. ${ }^{39}$

\section{Conclusion}

A first-price private-values auction experiment was conducted in which the same two bidders had to bid for a single item in two markets and under two different

\footnotetext{
${ }^{36} \mathrm{~A}$ level below 100 characterizes unrealized gains from trade.

${ }^{37}$ Testing for every auction period, the null hypothesis is rejected in favor of the alternative hypothesis that the efficiency under the symmetric condition is higher than under the asymmetric condition in nineteen of the twenty auction periods for $p<0.05$.

${ }^{38} \mathrm{~A}$ result similar to the one obtained with the dual-auction markets was observed for the first-price auction efficiency under each information condition in the single-auction markets. The percentage of POA and ME are consistently higher under the symmetric condition than under the asymmetric condition. These results are consistent with the more aggressive behavior of low-value bidders and the less aggressive behavior of high-value bidders under the asymmetric condition as compared to the symmetric condition.

${ }^{39}$ Notice that for the dual-auction markets, the actual proportion of optimal allocations for the asymmetric condition (74.80\%) was higher than at the risk-neutral equilibrium $(71.02 \%)$, but not for the symmetric, when the proportion of optimal allocations (87.14\%) was significantly lower than at equilibrium $(100 \%)$.
} 
information conditions. The purpose of this experiment was to examine the impact of information about the ranking of valuations on bidding behavior in first-price privatevalues auctions.

Experimental results indicate that, after information about the ranking of valuations was released, the two groups of bidders responded differently: As theory predicts, low-value bidders were inclined to bid more aggressively. Contrary to the theory's prediction, high-value bidders tended to bid less aggressively. By properly deviating after information was revealed, each group of bidders improved their average payoff per auction. However, while the probability of low-value bidders winning the item increased, the probability of high-value bidders winning it decreased. Therefore, as expected, the proportion of efficient allocations decreased with respect to the FPA under the symmetric condition. Contrary to the predictions, seller's expected revenue did not increase on a regular basis because high-value bidders decreased their bids once information was released.

Based on theoretical predictions, it was expected that both groups of bidders would increase their bids once information is released. This expectation presumes strategic thinking from high-value bidders: i.e., once they are aware that low-value bidders need to increase their bids in order to obtain the item, high-value bidders will be reluctant to take on the risk of submitting lower bids. The baseline of this prediction is that riskneutral fully rational bidders bid under the symmetric condition. In the laboratory, however, bidders were observed bidding well above the risk-neutral equilibrium under the symmetric condition. Based on this, high-value bidders were willing to take on the risk of submitting lower bids and increase their expected payoff once information about the ranking was released. This behavior seemed to be reinforced by the fact that, by decreasing their bids and moving in the direction of the optimal responses, bidders could still improve their average payoff conditional on winning.

In order to reconcile these two experimental results, I consider a risk-averse bidder that perceive the empirical bid function of the competing bidder. The resultant strategy reflect high-value bidders' incentives to reduce their bids after information 
is reveled and still tend to bid above the RNNE. 


\section{References}

[1] Athey, S. (2001) "Single Crossing Properties and the Existence of Pure Strategy Equilibria in Games of Incomplete Information," Econometrica, 69: 861-889.

[2] Beard, T. R. and R. Beil (1994) "Do people rely on the self-interested maximization of others? An experimental test," Management Science, 40, 252-62.

[3] Camerer, C.F. (2003), Behavioral game Theory: Experiments in Strategic Interaction, Russel Sage Foundation and Princeton University, New York.

[4] Capra, M., J. Goeree, R. Gomez and C. Holt (2002), "Learning and noisy equilibrium behavior in an experimental study of imperfect price competition," International Economic Review, 43, 613-36.

[5] Coppinger, V. M., V. L. Smith, and J. A. Titus (1980), "Incentives and behavior in English, Dutch and sealed-bid auctions," Economic Inquiry, 43, 1-22.

[6] Cox, J. C., B. Robertson and V. L. Smith (1982), "Theory and behavior of single object auctions," Research in Experimental Economics, JAI Press. Reprinted in Papers in Experimental Economics, V. L. Smith, Cambridge University Press, 1991, 580-594.

[7] Cox, J. C., V. L. Smith and Walker, J. M. (1988), "Theory and Individual Behavior in First-Price Auctions," Journal of Risk and Uncertainty, 1, 61-69.

[8] Elbittar, A.A. and M. U. Ünver (2001), "On Determination of Optimal Reserve Price in Auctions with Common Knowledge about Ranking of Valuations," Forthcoming in Advances in Economic Design, M. Sertel and S. Koray (eds.), Springer, Berlin.

[9] Fang, H. and S. Morris (2003), "Multidimensional Private Value Auctions" Cowles Foundation Discussion Paper No. 1423, Cowles Foundation for Research in Economics at Yale University.

[10] Güth, W., R. Ivanova-Stenzel and E. Wolfstetter (2004), "Bidding Behavior in Asymmetric Auctions: An Experimental Study," Discussion Paper at Max Planck Institute for Research Into Economic Systems and Humboldt University of Berlin.

[11] Harrison, G. (1989), "Theory and Misbehavior of First-Price Auctions," American Economic Review 79, 749-762.

[12] Isaac, R. M. and D. James (2000) "Just Who Are You Calling Risk Averse?," Journal of Risk and Uncertainty 20, 177-187.

[13] Kagel, J. H. and D. Levin (1986), "The Winner's Curse and Public Information in Common Value Auctions," American Economic Review, 76, 894-920. 
[14] Kagel, J. H., R. M. Harstad and D. Levin, (1987), "Information Impact and Allocation Rules in Auctions with Affiliated Private Values: A Laboratory Study," Econometrica, 55, 1275-1304.

[15] Kagel, J. H. (1995), "Auctions: A Survey of Experimental Research," in The Handbook of Experimental Economics, J. Kagel and A. Roth (eds.), Princeton University Press.

[16] Kaplan, T. R. and S. Zamir (2000), "The Strategic Use of Seller Information in Private-Values Auctions," Hebrew University of Jerusalem. Discussion Paper.

[17] Kim, J. and Y-K Che (2004), "Asymmetric Information about Rivals' Types in Standard Auctions," Games and Economic Behavior, 46, 383-397.

[18] Klemperer, P. (1999), "Auction Theory: A Guide to Literature," Journal of Economic Surveys, 13, 3, 227-286. (Re-printed in The Current State of Economic Science, 2, 711-766. S. Dahiya (ed.), 1999.)

[19] Klemperer, P. (2003), Auctions: Theory and Practice, Princeton University Press.

[20] Krishna, V. (2002), Auction Theory, Academic Press

[21] Landsberger, M., J. Rubinstein, E. Wolfstetter and S. Zamir (2001), "First-Price Auctions when the Ranking of Valuations is Common Knowledge," Review of Economic Design 6 3-4, 461-480.

[22] Marshall, R. C., M. J. Meurer, J-F. Richard and W. Stromquist (1994), "Numerical Analysis of Asymmetric First Price Auction," Games and Economic Behavior, 7, 193-220.

[23] McAdams, D. (2004) "Characterizing Equilibria in Asymmetric First-Price Auctions," MIT, Working Paper.

[24] McKelvey and T. Palfrey (1992) and games in which iterated reasoning increases payoffs (see, for example,

[25] Maskin, E. and J. Riley (2000), "Asymmetric Auctions," Review of Economic Studies, 67, 413-438

[26] Milgrom, P.R. and R. J. Weber (1982), "A Theory of Auctions and Competitive Bidding," Econometrica, 50, 1089-1122.

[27] Myerson, R. B. (1981), "Optimal Auction Design," Mathematics of Operation Research 6, 58-73.

[28] Nagel, R. (1995) "Unraveling in Guessing Games: An experimental Study," American Economic Review, 85, 1313-1326. 
[29] Pezanis-Christou, P. (2002), "On the Impact of Low-Balling: Experimental Results in Asymmetric Auctions," International Journal of Game Theory, 31, $1,69-89$.

[30] Pezanis-Christou, P. and A. Sadrieh (2003), "Elicited Bid Functions in (A)symmetric First-Price Auctions," UFAE and IAE Working Papers / Unitat de Fonaments de l'Anàlisi Econòmica (UAB) and Institut d'Anàlisi Econòmica (CSIC).

[31] Plum, M. (1992) "Characterization and Computation of Nash-Equilibria for Auctions with Incomplete Information," International Journal of Game Theory, 20, 4, 393-418.

[32] Riley, J. G., and W. F. Samuelson (1981), "Optimal Auctions," American Economic Review, 71, 381-392.

[33] Schotter, A., K. Weigelt and C. Wilson (1994), "A laboratory investigation of multiperson rationality and presentation effects," Games and Economic Behavior, 6, 445-68.

[34] Slonim, R. and A. E. Roth (1998), "Learning in High Stakes Ultimatum Games: An Experiment in the Slovak Republic," Econometrica, 66: 569-596.

[35] Vickrey, W. (1961), "Counterspeculations, auctions, and competitive sealed tender" Journal of Finance, 16, 8-37.

[36] Wolfstetter, E. (1996), "Auctions: An Introduction" Journal of Economic Surveys, 10, 367-420.

[37] Wolfstetter, E. (1999), Topics in Microeconomics, Cambrige University Press. 